\title{
Mirabegron as effective as oxybutynin for ureteral stent symptoms
}

\author{
Paulo Jaworski1,2* (D), Gregório Fadel Mello ${ }^{2}$ (D), Guilherme Monteiro Ferreira ${ }^{2}$ (D), \\ Maria Helena Oliveira ${ }^{3}$ (1), Rogerio de Fraga ${ }^{4}$
}

\section{SUMMARY}

OBJECTIVE: Ureteral stents usually cause pain and lower urinary tract discomfort. This study aimed to compare the effect of mirabegron with oxybutynin in relieving ureteral stent-related symptoms over time.

METHODS: A prospective, longitudinal, randomized, single-blinded study was conducted. Patients who had a ureteral stent inserted after urolithiasis treatment were classified into two groups and received either oxybutynin $5 \mathrm{mg} /$ day (Group O) or mirabegron $50 \mathrm{mg} /$ day (Group M). The Ureteral Stent Symptoms Questionnaire (USSQ) was applied on the 3rd, 6th, and 15th postoperative days. Group domain scores were compared, and a mixed linear model was used to better assess score differences.

RESULTS: Ureteral Stent Symptoms Questionnaire scores were similar in both groups during all three postoperative days ( $p>0.05$ ). A longitudinal analysis showed that global quality of life and general health improved over time, independently of the use of any of the medications $(p<0.05)$, while urinary symptoms and body pain scores were lower over time in participants receiving oxybutynin.

CONCLUSION: Both mirabegron and oxybutynin are equivalent in relieving ureteral stent symptoms. Moreover, some stent symptoms seem to decrease over time despite the use of medication.

KEYWORDS: Ureter. Stents. Ureteroscopy. Kidney calculi.

\section{INTRODUCTION}

Ureteral stent-related symptoms (USRS) are a common condition presented in patients undergoing endourological procedures. Lower abdomen and back pain usually occur along with lower urinary tract symptoms.

Alpha blockers are drugs very well studied for this purpose ${ }^{1-3}$. The understanding of their efficacy and low incidence of side effects may be an important factor that warrants the choice by many urologists ${ }^{2-4}$. USRS also recall those of hyperactive bladder, so antimuscarinics, such as oxybutynin, tolterodine, and solifenacin, were also studied ${ }^{5-8}$. Benefits of antimuscarinics are overridden by their potential side effects, such as xerostomy, xerophthalmy, blurred vision, constipation, and flushed skin.
Mirabegron is a beta-3 agonist drug that achieves an effective inhibition of cholinergic pathways without the occurrence of undesired side effects caused by antimuscarinics ${ }^{9,10}$.

This study aims to compare the effect of mirabegron with oxybutynin in relieving USRS over time.

\section{METHODS}

After project registration and approval by the institutional review board (authorization number 2.552.613/CAAE 85.174.18.0.0000.0103), we performed a prospective, randomized, single-blinded study. From April 2018 to March 2020, 48 patients who underwent urological procedures, in

\footnotetext{
${ }^{1}$ Hospital Universitário Evangélico Mackenzie, Urology Department - Curitiba (PR), Brazil.

¿Universidade Presbiteriana Mackenzie - Curitiba (PR), Brazil.

${ }^{3}$ Universidade Federal do Paraná, Statistics Department - Curitiba (PR), Brazil.

${ }^{4}$ Universidade Federal do Paraná, Urology Department - Curitiba (PR), Brazil.

*Corresponding author: pj@paulojaworski.com.br

Conflicts of interest: the authors declare there are no conflicts of interest. Funding: none.

Received on September 21, 2021. Accepted on September 21, 2021.
} 
which a ureteral stent was inserted, were enrolled. Consenting participants were completely informed regarding benefits and potential risks of using the medication.

Inclusion criteria were to have had a ureteral stent inserted after a minimally invasive urinary stone treatment procedure (either ureteroscopy, percutaneous nephrolithotripsy, or laparoscopy) or simple ureteral stent insertion without definite stone treatment for ureteral calculi. Exclusion criteria comprised patients with a ureteral stent inserted at the time of a previous surgery, pregnant women, forgotten ureteral stents, patients aged below 20 years and above 70 years, patients with known or reported overactive bladder, and men with symptomatic benign prostatic hyperplasia. The ureteral stent used was the same in all cases $\left(\right.$ Hummer $^{\mathrm{TM}}$ Ureteral Drainage Kit 6 Fr x $26 \mathrm{~cm}$ ).

Participants were randomly classified into two groups through a simple randomization design. The first group (Group O) received, at the day of discharge, oxybutynin $5 \mathrm{mg} /$ day, and the second group (Group $\mathrm{M}$ ) received mirabegron $50 \mathrm{mg} /$ day for 15 days. They were also prescribed nonsteroid anti-inflammatory drug (etodolac $400 \mathrm{mg}$ twice a day) for additional discomfort.

A Portuguese validated form of the Ureteral Stent Symptoms Questionnaire (USSQ) ${ }^{11}$ was given to all participants through a phone call in three different moments (3rd, 6th, and 15th postoperative days). The interviewer was not aware of which medication had been prescribed to the participant. The USSQ design contemplates six separate domains that embrace urinary symptoms, body pain, general health, work performance, sexual matters, and additional problems, as well as an overall global quality of life. In the original validation study, Joshi et al. stated that there is no single score for the whole questionnaire, as individual section scores represent separate domains and characteristics of the stent experience ${ }^{12}$. By acknowledging this assertion, after fully applying the questionnaire, we conducted separate analysis of four domains, namely, urinary symptoms $(\mathrm{U})$, body pain $(\mathrm{P})$, general health $(\mathrm{G})$, and additional problems (A), as well as global quality of life (GQ).

Out of total 48 participants, 24 were initially included in Group $\mathrm{O}$ and 24 in group M. Throughout the study, eight participants were excluded due to not completing telephonic interviews. Eventually, the final sample size was 40 (Group $\mathrm{O}=21$, Group $\mathrm{M}=19$ ).

Statistical analysis was performed using $\mathrm{R}$ language ( $\mathrm{R}$ Core Team, 2017). Numerical variables were represented through mean value and standard deviation. Student's $t$-test was used to compare numerical values at each interview time. Qualitative variables were represented by their absolute and relative frequencies. Fisher's exact test was used to analyze variables at each time of interview. A longitudinal analysis was carried out for each USSQ domain using a mixed linear model with random intercept in order to accommodate initial differences inherent to each participant and induce a correlation structure among observations of a participant in different moments ${ }^{13}$. The number of days after the procedure was used as numerical variable, and Group $\mathrm{O}$ was used as reference. For all statistical results, $\mathrm{p}<0.05$ was considered significant.

\section{RESULTS}

Data related to participants and procedures are given in Table 1. No statistical significance was found between the

Table 1. Participants' characteristics and procedures frequencies.

\begin{tabular}{|c|c|c|c|c|}
\hline & Total & Group O & Group M & p-value \\
\hline Number of participants (n) & 40 & 21 & 19 & - \\
\hline \multicolumn{5}{|l|}{ Gender, n (\%) } \\
\hline Female & $27(67.5)$ & $15(71.4)$ & $12(63.2)$ & \multirow{2}{*}{0.74} \\
\hline Male & $13(32.5)$ & $6(28.6)$ & $7(36.8)$ & \\
\hline Age, years (mean $\pm S D$ ) & $45.77 \pm 10.76$ & $47.9 \pm 8.68$ & $43.42 \pm 12.49$ & 0.2 \\
\hline Weight, kg (mean \pm SD) & $78.07 \pm 15.9$ & $78.8 \pm 18.02$ & $76.6 \pm 12.26$ & 0.78 \\
\hline Height, $\mathrm{cm}$ (mean \pm SD) & $164.8 \pm 11.23$ & $165.3 \pm 13.02$ & $163.8 \pm 7.63$ & 0.78 \\
\hline \multicolumn{5}{|l|}{ Procedures } \\
\hline Cystoscopic double-J insertion, n (\%) & $14(35)$ & $8(38.1)$ & $6(31.6)$ & \multirow{4}{*}{0.84} \\
\hline $\begin{array}{l}\text { Laparoscopic pyelolithotomy or } \\
\text { ureterolithotomy, n (\%) }\end{array}$ & $3(7.5)$ & $1(4.8)$ & $2(10.5)$ & \\
\hline Percutaneous nephrolithotripsy, n (\%) & $1(2.5)$ & $1(4.8)$ & $0(0)$ & \\
\hline Ureterolithotripsy, n (\%) & $22(55)$ & $11(52.4)$ & $11(57.9)$ & \\
\hline
\end{tabular}


groups. Frequency of urological procedures between the groups was similar.

Overall results for domain scores at each interview are shown in Table 2. None of the scores showed statistical difference between the groups at any of the interviews.

Random intercept analysis results for all domains are displayed in Table 3. Statistical results for urinary symptoms reveal a significant interaction effect $(\mathrm{p}=0.03)$ between the number of days and the group to which the patient belongs, meaning that the effect caused in each group is different for each moment of the analysis. As Group $\mathrm{O}$ is the reference for this model, the intercept value can be interpreted as the estimate value for urinary symptoms for Group $\mathrm{O}$ at time zero. Group effect, in this case, varies according to the number of days.

Analysis of the body pain domain shows significant interactions for both time $(\mathrm{p}<0.05)$ and Group $(\mathrm{p}=0.02)$, indicating that both time and medication may play a role in the participant's symptoms, benefiting patients in Group O. General health analysis shows a significant time effect $(\mathrm{p}<0.05)$, with similar decrease in both groups. Global quality of life reveals a significant time effect for both groups $(\mathrm{p}<0.05)$ but no difference between them.

\section{DISCUSSION}

The use of antimuscarinics (oxybutynin and tolterodine) has been widely studied, with data showing benefit when used

Table 3. Linear mixed model with random intercept analysis of the domains.

\begin{tabular}{|c|c|c|}
\hline Urinary symptoms & Estimative & p-value \\
\hline Group M compared with Group O & -1.49 & 0.51 \\
\hline Days after procedure & -0.15 & 0.21 \\
\hline Group M interaction: Days & 0.40 & $0.03 *$ \\
\hline Body pain & Estimative & p-value \\
\hline $\begin{array}{l}\text { Group M compared with } \\
\text { Group O }\end{array}$ & -2.72 & 0.40 \\
\hline Days after procedure & -0.71 & $0.00 *$ \\
\hline Group M interaction: Days & 0.41 & $0.02 *$ \\
\hline General health & Estimative & p-value \\
\hline $\begin{array}{l}\text { Group M compared with } \\
\text { Group O }\end{array}$ & 0.26 & 0.89 \\
\hline Days after procedure & -0.26 & $0.00 *$ \\
\hline Group M interaction: Days & 0.07 & 0.41 \\
\hline Additional problems & Estimative & p-value \\
\hline $\begin{array}{l}\text { Group M compared with } \\
\text { Group O }\end{array}$ & 0.84 & 0.21 \\
\hline Days after procedure & -0.04 & 0.10 \\
\hline Group M interaction: Days & 0.02 & 0.55 \\
\hline Global quality of life & Estimative & p-value \\
\hline $\begin{array}{l}\text { Group M compared with } \\
\text { Group O }\end{array}$ & -0.33 & 0.42 \\
\hline Days after procedure & -0.07 & $0.00 *$ \\
\hline Group M interaction: Days & 0.03 & 0.15 \\
\hline
\end{tabular}

Table 2. Domains' scores (mean \pm SD) at different times of interview.

\begin{tabular}{l|c|c|c}
\hline 3rd postoperative day & Group O & Group M & p-value \\
\hline Urinary symptoms & $29.62 \pm 5.08$ & $28.95 \pm 6.84$ & 0.72 \\
\hline Body pain & $24.38 \pm 13.25$ & $22.79 \pm 9.16$ & 0.66 \\
\hline General health & $14.38 \pm 6.09$ & $14.95 \pm 7.34$ & 0.79 \\
\hline Additional problems & $5.90 \pm 1.89$ & $6.84 \pm 2.22$ & 0.16 \\
\hline Global quality of life & $4.76 \pm 1.30$ & $4.53 \pm 1.39$ & 0.58 \\
\hline 6th postoperative day & Group O & Group M & p-value \\
\hline Urinary symptoms & $26.52 \pm 4.93$ & $27.89 \pm 6.46$ & 0.45 \\
\hline Body pain & $20.1 \pm 9.91$ & $20 \pm 9.14$ & 0.97 \\
\hline General health & $12.57 \pm 5.60$ & $13.11 \pm 6.38$ & 0.78 \\
\hline Additional problems & $5.43 \pm 1.57$ & $6.37 \pm 2.11$ & 0.12 \\
\hline Global quality of life & $4.09 \pm 1.09$ & $4 \pm 1.20$ & 0.79 \\
\hline 15th postoperative day & Group O & Group M & -value \\
\hline Urinary symptoms & $27 \pm 7.52$ & $31.32 \pm 8.82$ & 0.11 \\
\hline Body pain & $15.14 \pm 8.37$ & $18.58 \pm 9.02$ & 0.22 \\
\hline General health & $10.9 \pm 4.84$ & $12.21 \pm 6.30$ & 0.47 \\
\hline Additional problems & $5.29 \pm 2.08$ & $6.47 \pm 2.36$ & 0.1 \\
\hline Global quality of life & $3.75 \pm 1.41$ & $3.95 \pm 0.91$ & 0.6 \\
\hline
\end{tabular}

SD: standard deviation. 
alone or in association with alpha blockers (alfuzosin and tamsulosin) $)^{6,7}$. Mirabegron, a beta-3 agonist approved for OAB symptoms, has also been proved to perform a selective alpha-1a and alpha-1d adrenergic antagonism ${ }^{14}$ in an experimental scenario. In addition, Shen et al. ${ }^{15}$ recently demonstrated, through immunochemistry analysis, the expression of all beta-adrenergic receptor subtypes in the mucosa and muscular layers of the human ureter. These findings reinforce a theoretical benefit for mirabegron to relief USRS.

Results shown in Table 2 support mirabegron to be as effective as oxybutynin in relieving USRS. Similarly, Tae et al. first reported that mirabegron markedly reduced body pain when compared with placebo ( 21.96 versus $13.96, \mathrm{p}=0.007)$ but did not observe significant differences in the other domains ${ }^{16}$. In this study, a subanalysis of the urinary symptoms' domain revealed a significant improvement only in specific scores that were mainly related to storage symptoms ${ }^{16}$. Yavuz et al. performed a prospective placebo-controlled study comparing tamsulosin and mirabegron with a lesser use of analgesics by patients in the mirabegron group, although no reduction was seen in urinary symptoms scores when compared with placebo ${ }^{17}$. Finally, Cinar et al. described a significant reduction in USRS with the use of mirabegron as a monotherapy in a retrospective study ${ }^{18}$. Therefore, this is the first study that compares mirabegron with an antimuscarinic for USRS.

This study provides an in-depth understanding about ureteral stent symptoms over time. According to Liu et al., in a study that compared tamsulosin, solifenacin, and their combination with placebo, multiple interviews were performed over time and the authors concluded that USRS decreased spontaneously in all groups, including placebo, within the four initial days ${ }^{19}$. In our study, with the mixed linear model with random intercept, we could understand how domains' scores behave over time despite the use of the drugs without the need for a placebo group. Within the body pain domain, time played a role in easing the symptoms $(\mathrm{p}<0.05)$. For this domain specifically, there is also a difference between the groups. There was less reduction of pain during time in Group $M$ than in Group $\mathrm{O}(\mathrm{p}<0.02)$. However, this finding does not impact the overall score comparison at different interview dates. Regarding urinary symptoms, there is also a reduction of the score over time, but this reduction was significantly important in Group $\mathrm{O}$ alone $(\mathrm{p}=0.03)$. This finding coincides with that suggested by Tae et al. ${ }^{16}$ and Yavuz et al. ${ }^{17}$, whose studies indicate that mirabegron did not show improvement in urinary symptoms when compared with placebo. Again, the differences in the overall score on interview dates did not show statistical significance. Time effect could be demonstrated in general health $(\mathrm{p}<0.05)$ and global quality of life $(\mathrm{p}<0.05)$ domains.

The small number of patients in each group is a limitation of this study. Our institution suffered important interruption of the surgical routine due to the coronavirus disease 2019 pandemic, which significantly impacted patient enrollment and data collection. We are also aware that this study has the limitation of not having better homogenized groups regarding the type of procedure. Nevertheless, our sample comprehend an excerpt of patients with ureteral stents that represent a reality not far from other services and practices. We consider this study an important contribution to the efforts in finding a better medication to ease USRS in real practice.

\section{CONCLUSION}

Mirabegron and oxybutynin are equivalent in relieving ureteral stent symptoms. We also found evidence supporting the hypothesis that some stent symptoms simply decrease over time, independently of medication. Further studies are needed to complement our findings.

\section{ACKNOWLEDGMENTS}

The authors appreciate the support of all assistants, residents, and staff of Urology Department at Mackenzie Evangelical University Hospital during this study, despite all the negative impacts coronavirus disease 2019 pandemic caused to our practice and service.

\section{AUTHORS" CONTRIBUTIONS}

PJ: Conceptualization, Data curation, Writing - original draft, Writing - review \& editing. GFM: Conceptualization, Data curation. GMF: Data curation, Project administration. MHO: Formal Analysis, Writing - original draft. RF: Conceptualization, Supervision, Writing - review \& editing.

\section{REFERENCES}

1. Beddingfield R, Pedro RN, Hinck B, Kreidberg C, Feia K, Monga M. Alfuzosin to relieve ureteral stent discomfort: a prospective, randomized, placebo controlled study. J Urol. 2009;181(1):170-6. https://doi.org/10.1016/j.juro.2008.09.026
2. Damiano R, Autorino R, De Sio M, Giacobbe A, Palumbo IM, D'Armiento M. Effect of tamsulosin in preventing ureteral stent-related morbidity: a prospective study. J Endourol 2008;22(4):651-6. https://doi.org/10.1089/end.2007.0257 
3. Dellis AE, Keeley Junior FX, Manolas $V$, Skolarikos AA. Role of $\alpha$-blockers in the treatment of stent-related symptoms: a prospective randomized control study. Urology. 2014;83(1):5661. https://doi.org/10.1016/j.urology.2013.08.067

4. Kwon JK, Cho KS, Oh CK, Kang DH, Lee H, Ham WS, et al. The beneficial effect of alpha-blockers for ureteral stent-related discomfort: systematic review and network meta-analysis for alfuzosin versus tamsulosin versus placebo. BMC Urol. 2015;15:55. https://doi.org/10.1186/s12894-015-0050-5

5. Norris RD, Sur RL, Springhart WP, Marguet CG, Mathias BJ, Pietrow PK, et al. A prospective, randomized, double-blinded placebo-controlled comparison of extended release oxybutynin versus phenazopyridine for the management of postoperative ureteral stent discomfort. Urology. 2008;71(5):792-5. https:// doi.org/10.1016/j.urology.2007.11.004

6. Maldonado-Avila M, Garduno-Arteaga L, JungfermannGuzman R, Manzanilla-Garcia HA, Rosas-Nava E, ProcunaHernandez N, et al. Efficacy of Tamsulosin, Oxybutynin, and their combination in the control of double-j stent-related lower urinary tract symptoms. Int Braz J Urol. 2016;42(3):487-93. https://doi.org/10.1590/S1677-5538.IBJU.2015.0186

7. Park SC, Jung SW, Lee JW, Rim JS. The effects of tolterodine extended release and alfuzosin for the treatment of double-j stent-related symptoms. J Endourol. 2009;23(11):1913-7. https://doi.org/10.1089/end.2009.0173

8. Boulos V. 1077 Do alpha blockers (tamsulosin) and/or anticholinergics (tolterodine) improve indwelling double-J related symptoms after ureteroscopy? Eur Urol Open Sci. 2015;14(2):E1077. https://doi.org/10.1016/S15699056(15)61065-X

9. Yamaguchi O, Marui E, Kakizaki H, Homma Y, Igawa Y, Takeda $\mathrm{M}$, et al. Phase III, randomised, double-blind, placebo-controlled study of the $\beta 3$-adrenoceptor agonist mirabegron, $50 \mathrm{mg}$ once daily, in Japanese patients with overactive bladder. BJU Int. 2014;113(6):951-60. https://doi.org/10.1111/bju.12649

10. Nambiar AK, Bosch R, Cruz F, Lemack GE, Thiruchelvam N, Tubaro A, et al. EAU Guidelines on assessment and nonsurgical management of urinary incontinence. Eur Urol. 2018;73(4):596609. https://doi.org/10.1016/j.eururo.2017.12.031
11. Santos RCM, Moreira RSL, Roza BA. Validação do instrumento Ureteral Stent Symptom Questionnaire para uso no Brasil. Acta Paul Enferm. 2016;29(2):198-204. https://doi. org/10.1590/1982-0194201600028

12. Joshi HB, Newns N, Stainthorpe A, MacDonagh RP, Keeley Junior FX, Timoney AG. Ureteral stent symptom questionnaire: development and validation of a multidimensional quality of life measure. J Urol. 2003;169(3):1060-4. https://doi. org/10.1097/01.ju.0000049198.53424.1d

13. Diaz FJ, Yeh HW, Leon J. Role of Statistical Randomeffects linear models in personalized medicine. Curr Pharmacogenomics Person Med. 2012;10(1):22-32. https:// doi.org/10.2174/1875692111201010022

14. Alexandre EC, Kiguti LR, Calmasini FB, Silva FH, Silva KP, Ferreira $\mathrm{R}$, et al. Mirabegron relaxes urethral smooth muscle by a dual mechanism involving $\beta 3$-adrenoceptor activation and $\alpha 1$ -adrenoceptor blockade. Br J Pharmacol. 2016;173(3):415-28. https://doi.org/10.1111/bph.13367

15. Shen $\mathrm{H}$, Chen Z, Mokhtar AD, Bi X, Wu G, Gong S, et al. Expression of $\beta$-adrenergic receptor subtypes in human normal and dilated ureter. Int Urol Nephrol. 2017;49(10):1771-8. https://doi.org/10.1007/s11255-017-1667-y

16. Tae BS, Cho S, Jeon BJ, Choi H, Park JY, Cho SY, et al. Does mirabegron relieve ureteric stent-related discomfort? A prospective, randomized, multicentre study. BJU Int. 2018;122(5):866-72. https://doi.org/10.1111/bju.14416

17. Yavuz A, Kilinc MF, Aydin M, Ofluoglu Y, Bayar G. Does tamsulosin or mirabegron improve ureteral stent-related symptoms? A prospective placebo-controlled study. Low Urin Tract Symptoms. 2021;13(1):17-21. https://doi.org/10.1111/luts.12320

18. Cinar O, Tanidir Y, Ozer S, Cizmeci S, Erbatu O, Ozdemir T, et al. Effects of mirabegron on JJ stent-related symptoms: a multicentric study. Int J Clin Pract. 2021;75(2):e13857. https:// doi.org/10.1111/ijcp.13857

19. Liu Q, Liao B, Zhang R, Jin T, Zhou L, Luo D, et al. Combination therapy only shows short-term superiority over monotherapy on ureteral stent-related symptoms - outcome from a randomized controlled trial. BMC Urol. 2016;16(1):66. https:// doi.org/10.1186/s12894-016-0186-y 